\title{
On the intrusion of polyethylene glycol during osmotic tests
}

\author{
S. TRIPATHY*, M. Y. M. TADZA* and H. R. THOMAS*
}

\begin{abstract}
In the laboratory, semi-permeable membranes and polyethylene glycol (PEG) solutions are used for applying suction in soils using the osmotic technique. In this study, the pore structures of cellulose semi-permeable membranes with molecular weight cut-off values of 3500 and 14000 were examined via an atomic force microscope (AFM). Fourier transform infrared (FTIR) spectroscopy was used to identify any degradation of PEG molecules with elapsed time. Freshly prepared PEG solutions and solutions aged for 15 days were considered for this purpose. Osmotic tests were carried out on initially saturated MX80 bentonite specimens at two suction levels (0.44 and 7.04 MPa). Comparison of the AFM images of the semi-permeable membranes before and after the osmotic tests clearly revealed that the pore size of the semi-permeable membranes increased significantly, particularly at the higher applied suction that enabled passing of PEG molecules into the clay specimens. FTIR spectrums of PEG 20000 and PEG 6000 did not provide any evidence of degradation of the PEG molecules with elapsed time.
\end{abstract}

KEYWORDS: clays; expansive soils; laboratory tests; microscopy; suction

ICE Publishing: all rights reserved

\section{INTRODUCTION}

In the laboratory, suction of soils can be controlled by the osmotic technique. A soil specimen is brought in contact with a solution of polyethylene glycol (PEG) of predetermined molecular weight separated by a semi-permeable membrane. By varying the concentration of the PEG solution, predetermined osmotic gradients can be created. In the event of equalisation of the osmotic suction on either side of the semi-permeable membrane, the method controls the matric suction of soils (Zur, 1966). Several researchers have used the osmotic technique to study the water retention behaviour of soils (Fleureau et al. 1993; Marcial et al., 2002; Williams \& Shaykewich, 1969; Zur, 1966). Similarly, the technique has been used to study the volume change behaviour of soils as affected by changes in the soil suction (Cui \& Delage, 1996; Cuisinier \& Masrouri, 2005; Delage \& Cui, 2008a; Delage et al., 1998; Dineen \& Burland, 1995; Kassiff \& Ben Shalom, 1971; Monroy et al., 2007).

A review of the literature suggested that the osmotic technique has been extensively used for applying suctions less than $1.5 \mathrm{MPa}$, but studies on the applications of the osmotic technique for higher suctions are limited (Delage \& Cui, 2008a). The main limitation of the osmotic technique is associated with the intrusion of PEG into soil specimens (Delage \& Cui, 2008b; Tarantino \& Mongiovi, 2000; Williams and Shaykewich, 1969). It has been hypothesised in the past that the intrusion of PEG occurs either due to failure of the semi-permeable membrane in restricting the passage of PEG molecules or a degradation of PEG molecules into smaller sizes.

In this study, atomic force microscope (AFM) studies were carried out to investigate the pore size of semipermeable membranes before and after osmotic tests. Fourier transform infrared (FTIR) spectroscopy was used

Manuscript received 28 February 2011; first decision 5 May 2011; accepted 9 June 2011.

Published online at www.geotechniqueletters.com on 18 July 2011.

*School of Engineering, Cardiff University, Cardiff, UK to explore any changes in the molecular structure of PEG molecules with elapsed time.

\section{LITERATURE REVIEW}

Cellulose acetate membranes are generally used in osmotic tests. Slatter et al. (2000) and Monroy et al. (2007) stated that the membranes are susceptible to bacteria attacks in a longer testing period. The problem, however, can be minimised by adding penicillin to improve the bacteria resistance of the membranes (Kassiff \& Ben Shalom, 1971). Similarly, due to the amorphous gel-like nature of regenerated cellulose, the membranes are known to be vulnerable against mechanical strain (SL, 2007). The pore size of semi-permeable membranes is usually designated by their molecular weight cut-off (MWCO) value. Kim et al. (1994) stated that the MWCO alone would not be sufficient for membrane characterisation as the actual pore size of a membrane may differ quite significantly from that specified by the manufacturer. There are several methods available to study the pore structure of a semi-permeable membrane, such as the use of an AFM, scanning electron microscopy (SEM), thermoporometry and biliquid permporometry (Elimelech et al., 1997; Kim et al., 1994). AFM studies do not require specimens to be treated with conductive material, which could possibly alter the properties of the membrane.

PEG is a hydrophilic polymer made up of molecular chains having the chemical formula: $\mathrm{HO}-\left[\mathrm{CH}_{2}-\mathrm{CH}_{2}-\mathrm{O}\right]_{n}{ }^{-}$ $\mathrm{H}$ (Delage \& Cui, 2008a). The chain length $n$ of the polymer influences the molecular weight. The size of PEG molecules is usually much larger in a solution than any other molecules of comparable molecular weight (Harris, 1992; Squire, 1985). For hydrated molecules in solutions, the hydrodynamic radius $R_{\mathrm{h}}$ is generally used to describe the molecular size (Harris, 1992; Himmel \& Squire, 1988).

Lentsch et al. (1993) proposed an empirical relationship (equation (1)) between the molecular weight and the hydrodynamic diameter of PEG molecules for the case of constant density of molecules. Using equation (1), for a known molecular weight (MW) of PEG, the hydrodynamic 


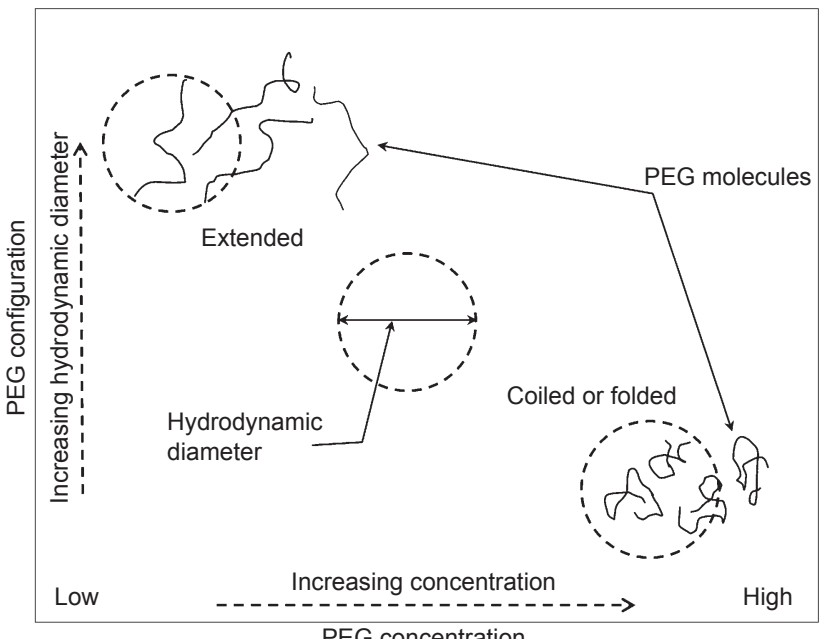

Fig. 1. Schematic representation of $P E G$ molecular chain configuration as a function of PEG concentration

diameter of PEG molecules ( $d_{\mathrm{PEG}}$, in nanometres) can be calculated. For example, the size of molecules for PEG 6000 can be found to be about $4.0 \mathrm{~nm}$, whereas it is about $7 \cdot 0 \mathrm{~nm}$ for PEG 20000 .

$$
d_{\mathrm{PEG}}=0.09(\mathrm{MW})^{0.44}
$$

Equation (1) can also be used for estimating the pore sizes of semi-permeable membranes. The calculated pore sizes of semi-permeable membranes with a MWCO of 3500 and 14000 are about 3.3 and $6.0 \mathrm{~nm}$, respectively. A combination of the semi-permeable membrane to be used, along with a PEG grade, can be decided based on equation (1).

\section{Table 1. Properties of MX80 bentonite}

\begin{tabular}{l|c}
\hline Liquid limit $w_{\mathrm{l}}: \%$ & 437 \\
Plastic limit $w_{\mathrm{p}}: \%$ & 63 \\
Shrinkage limit $w_{\mathrm{s}}: \%$ & $12 \cdot 2$ \\
Specific surface area: $\mathrm{m}^{2} / \mathrm{g}$ & 676 \\
Cation exchange capacity: meq/100g & $90 \cdot 3$ \\
\hline
\end{tabular}

According to Michel \& Kaufman (1973) and Minagawa et al. (1994), for PEG solutions of low concentration, longer PEG chains are usually formed due to a lesser interaction between the PEG molecules. On the other hand, the interaction between PEG chains increases with an increase in the concentration of solution, which is manifested in the formation of smaller coiled or folded structures (Cosgrove, 2005) of the PEG molecules. Figure 1 shows a schematic representation of possible reduction in the hydrodynamic diameter due to an interaction of PEG chains with an increase in concentration of PEG solution. In the case of an unaltered pore size of semi-permeable membrane during a test, a reduction in the size of PEG molecules alone may enable passing of PEG into the soil-water system and subsequently reduce the efficiency of the osmotic system (Iwata et al., 1988; Kemper \& Evans, 1963). Han et al. (1995) stated that PEGs are susceptible to oxidative degradation in the presence of air, which may lead to lowering of the molecular weight. Other possible causes of degradation of PEGs are associated with interactions of molecules of PEG with the semi-permeable membrane used and with expelled ions from the pore fluid of soil-water systems. Studies concerning the degradation of hydrated PEGs with elapsed time are crucial in order to better the understanding of the osmotic system in controlling matric suction of soils.

Degradation of PEG can be studied using various techniques, such as x-ray diffraction (XRD), x-ray photoelectron spectroscopy (XPS) and Fourier transform infrared (FTIR) spectroscopy (Beamson et al., 2000; Celina et al., 1997; Han et al., 1995). FTIR spectroscopy is a rapid and non-destructive technique for identifying molecular structures and degradation of organic-based polymers (Han et al., 1995; Roberts \& Caserio, 1965).

\section{PRESENT STUDY}

Osmotic tests were carried out on initially saturated MX80 bentonite specimens. The properties of the bentonite are presented in Table 1. The tests were carried out following the experimental method suggested by Delage et al. (1998). Bentonite-water mixtures were prepared at a targeted water content equal to about $1 \cdot 2$ times the liquid limit of the

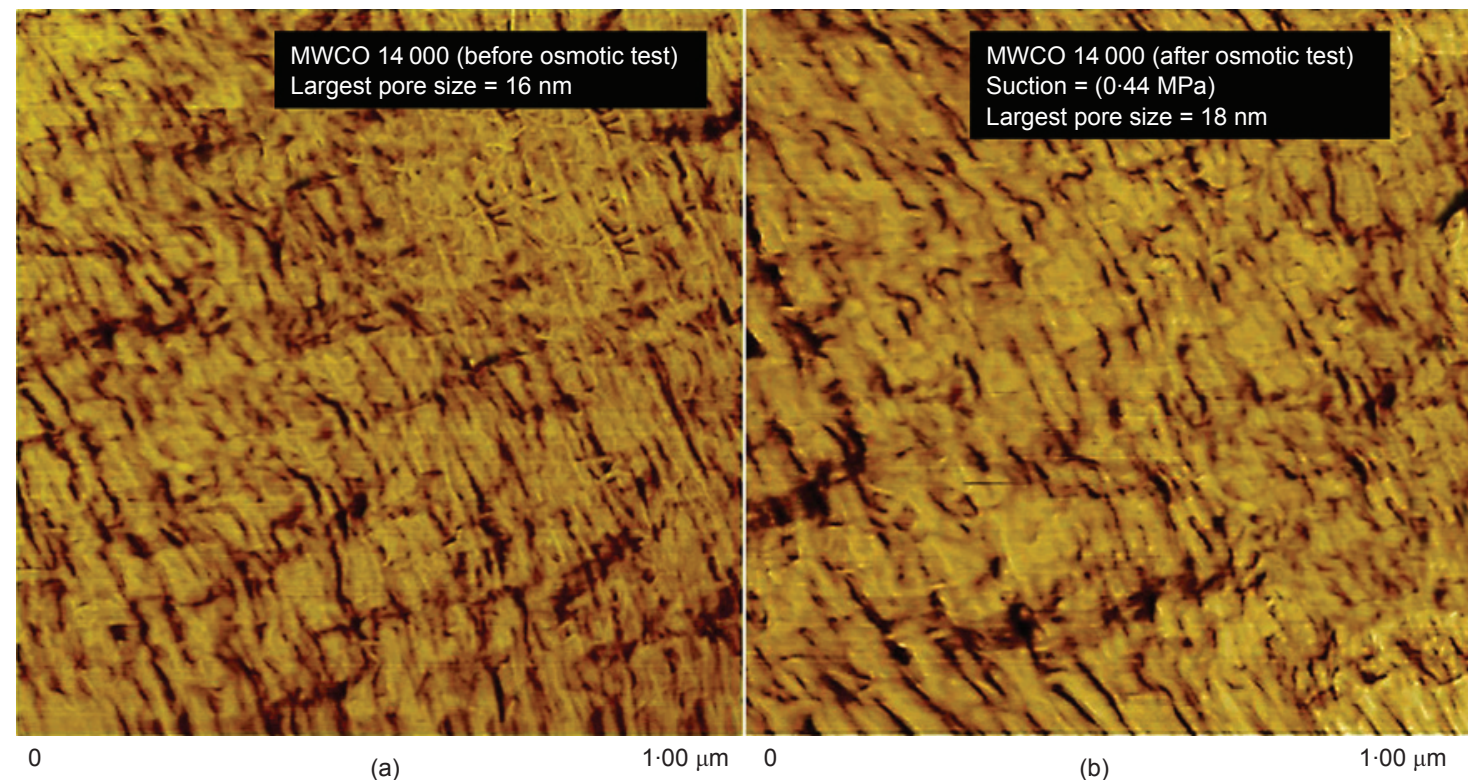

Fig. 2. AFM images of MWCO 14000 semi-permeable membrane (a) before and (b) after osmotic test 


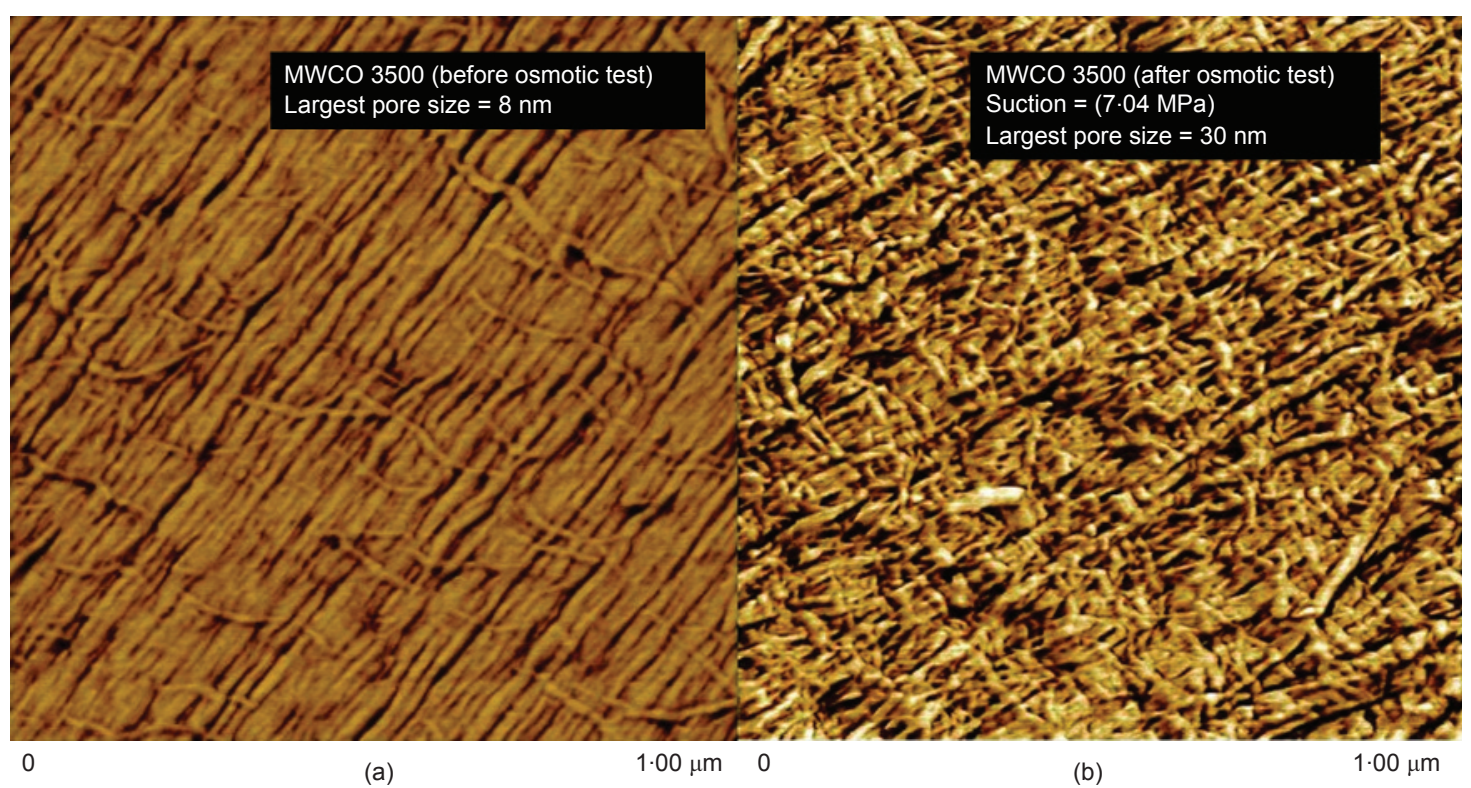

Fig. 3. AFM images of MWCO 3500 semi-permeable membrane (a) before and (b) after osmotic test

bentonite. Two suction levels were considered. PEG 20000 was used along with Spectra/Por ${ }^{\circledR}$ MWCO 14000 membrane for applying a suction of $0.44 \mathrm{MPa}$, whereas PEG 6000 was used along with Spectra/Por ${ }^{\circledR}$ MWCO 3500 membrane for applying a suction of 7.04 MPa. Deionised water was used for preparing the bentonite-water mixtures and the PEG solutions. The solutions were prepared according to the calibration curve reported by Delage et al. (1998). The semipermeable membranes were immersed in deionised water for approximately $30 \mathrm{~min}$ to remove the glycerine preservative coating prior to the tests. The tests were carried out for a period of 15 days in both cases.

A Multimode III scanning probe microscope from Veeco (Digital Instruments) was used to scan the topography of the membranes. After completion of the osmotic tests, the membranes were carefully removed and rinsed before being directly transferred to the device.

A PerkinElmer FTIR System 2000 was used for identifying the chemical and molecular changes of the PEG solutions. FTIR spectroscopy generates spectrum patterns according to the infrared intensity (i.e. wavenumber or wavelength) and the fraction of infrared transmitted by certain chemical bonds (Roberts \& Caserio, 1965). The spectrum patterns are then interpreted by comparing them with an infrared library of patterns for specific molecules (Morrison \& Boyd, 1983). A sudden shift or distortion to the spectrum will generally indicate degradation or changes to either chemical bonds or molecule structure (Celina et al., 1997; Han et al., 1995). Freshly prepared PEG solutions and solutions prepared and stored for a period of 15 days were tested for comparison.

\section{RESULTS AND DISCUSSION \\ Osmotic tests}

At each of the applied suctions, two specimens were tested. The bentonite specimens tested at an applied suction of 7.04 $\mathrm{MPa}$ were noted to have glazed patches on their surfaces, indicating that an intrusion of PEG occurred during the tests. However, this was not evident in case of the specimens tested at an applied suction of $0.44 \mathrm{MPa}$. The glazed patches on the surfaces of the specimens turned white once the specimens were oven dried for determination of the water contents. The average water contents of the specimens after
15 days of equilibration period were found to be $78 \cdot 0$ and $23.0 \%$ for applied suctions of 0.44 and $7 \cdot 04 \mathrm{MPa}$, respectively.

\section{AFM Studies}

Figures 2 and 3 present typical AFM phase images of membranes of MWCO 14000 and 3500. For each membrane type, the AFM images before and after the osmotic tests are presented. The AFM images showed that the semipermeable membranes were composed of well-organised regenerated cellulose strands or chains that interlock onto one another to form a mesh-like formation. These cross-link structures act like pores (SL, 2007). The pore-size was found to vary from 1.0 to $16.0 \mathrm{~nm}$ for the membrane with a MWCO of 14000 (Fig. 2(a)), whereas it varied from 1.0 to $8 \cdot 0 \mathrm{~nm}$ for the membrane with a MWCO of 3500 (Fig. 3(a)). The measured pore-sizes in this study were found to be somewhat greater than the manufacturer's specifications.

The AFM images of the membranes after the osmotic tests clearly revealed that the pore-size altered significantly at an

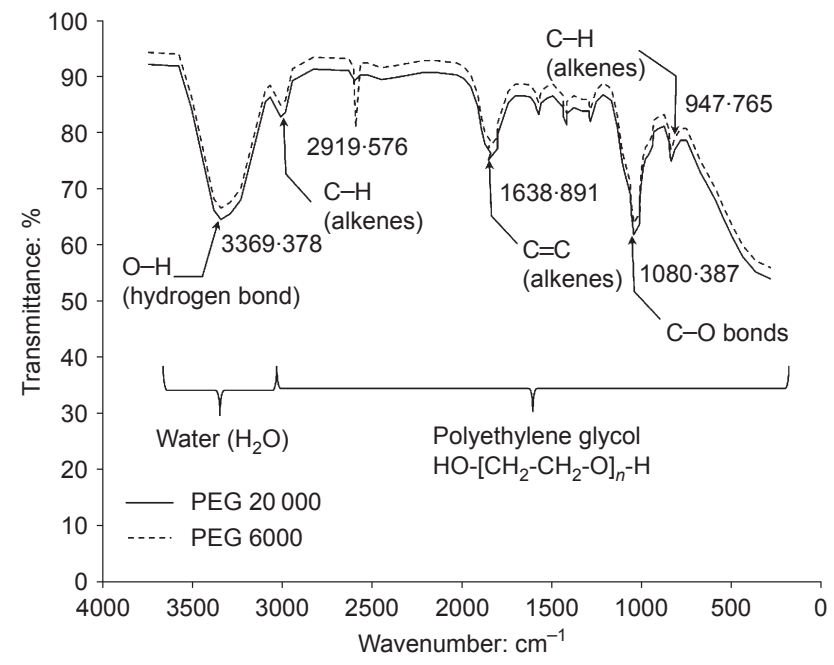

Fig. 4. Comparison of FTIR transmittance spectra for PEG 20000 and PEG 6000 


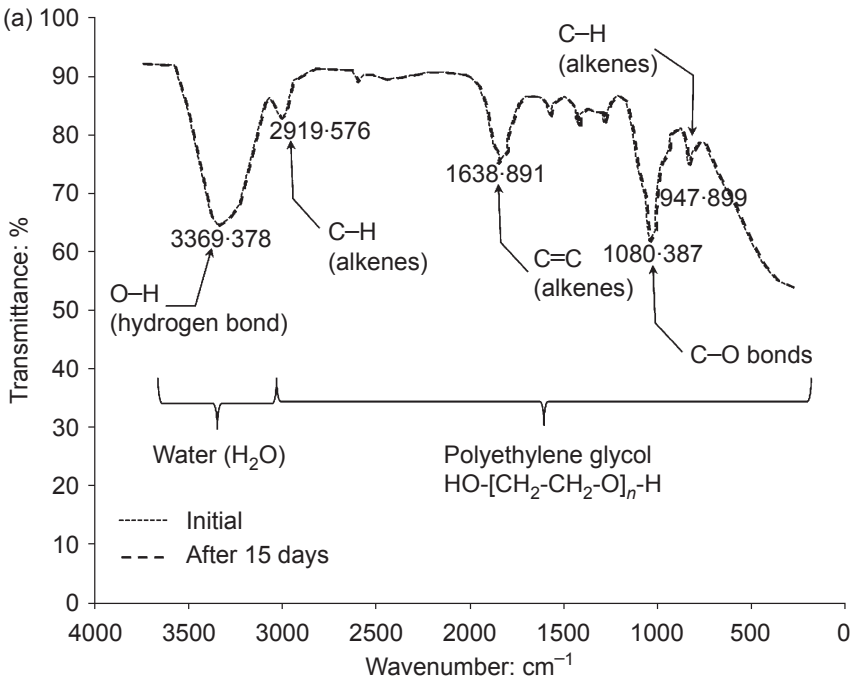

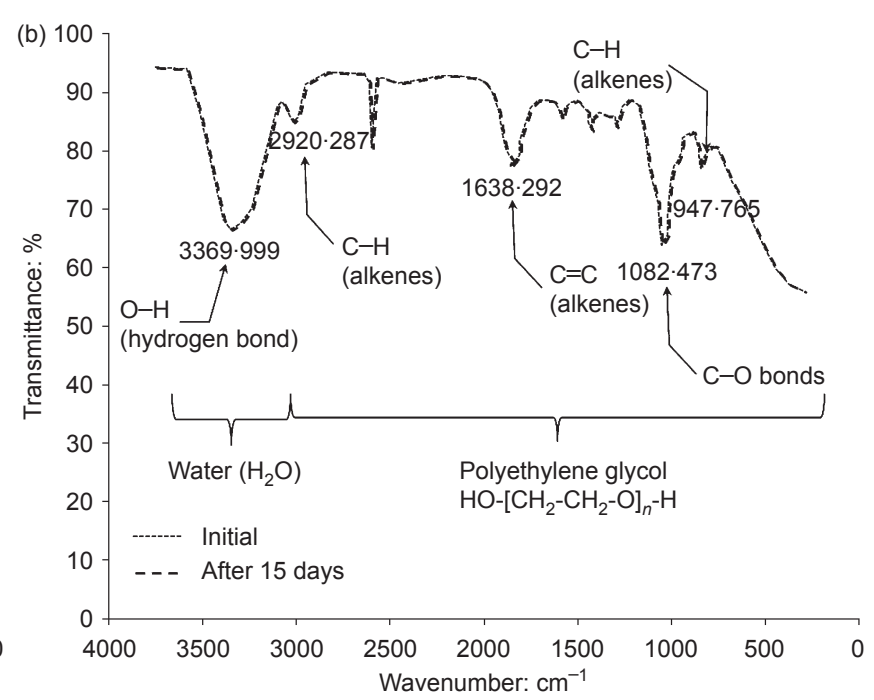

Fig. 5. FTIR transmittance spectra of (a) PEG 20000 (b) PEG 6000

applied suction of 7.04 MPa. In this case, the maximum pore size increased to about $30 \cdot 0 \mathrm{~nm}$ (Fig. 3(b)). For the membrane with a MWCO of 14000 , the pore size after the osmotic test remained somewhat similar; however, the largest pore size increased to a maximum of about $18 \cdot 0 \mathrm{~nm}$ (Fig. 2(b)).

\section{FTIR analysis}

The FTIR spectrums of freshly prepared PEG 20000 and PEG 6000 solutions are presented in Fig. 4. The spectra are generated based on the amount of infrared transmitted by the solutions corresponding to various wavenumbers. Figure 4 clearly shows that molecules of both PEG types consist primarily of carbon, oxygen and hydrogen covalent bonds (i.e. between wavenumbers of 0 and $2920 \mathrm{~cm}^{-1}$ ). The spectra corresponding to a wavenumber of approximately $3370 \mathrm{~cm}^{-1}$ are for $\mathrm{O}-\mathrm{H}$ bonds and for the deionised water that was used for preparing the solutions. The FTIR spectra of the two PEG solutions were found to be very nearly similar, indicating a similarity in their chemical composition. On the other hand, the FTIR transmittance spectrum for PEG 6000 was greater than that for PEG 20000 . This greater transmittance is primarily due to the shorter chain length of PEG 6000 that absorbed a lesser fraction of the infrared. Delage \& Cui (2008a) stated that a longer chain may be expected for PEG 20000 as compared with that for PEG 6000 .

Figure 5 compares the FTIR spectra of freshly prepared PEG solutions and the solutions aged for 15 days. Overlapping of the spectra in Figs 5(a) and (b) clearly indicates that the PEG molecules did not degrade, at least up to a period of 15 days. Although the test results indicate that the PEGs used in this study were non-degradable in solutions at ambient conditions, this does not preclude any possible degradation of hydrated PEGs during osmotic tests. This aspect was beyond the scope of the current study and needs further examination. On the other hand, the results showed that significant alterations in the pore size of the semi-permeable membrane used at the higher applied suction may still enable passing of PEG molecules into soil systems.

\section{CONCLUSIONS}

The pore size of cellulose semi-permeable membranes with MWCO values of 3500 and 14000 were studied before and after osmotic tests. The results showed that, irrespective of the magnitude of applied suction, some alterations in pore size occurred during the osmotic tests. Changes in the pore size of the membrane with MWCO of 3500 were found to be significant at an applied suction of $7.04 \mathrm{MPa}$; the maximum pore size increased from 8.0 to $30 \cdot 0 \mathrm{~nm}$. FTIR spectra of PEG solutions did not provide any evidence of degradation of hydrated PEG molecules with elapsed time. However, PEG 6000, with a lower molecular weight, exhibited higher transmittance due to its shorter chain length. Therefore, at higher applied suction, both an increase in the pore size of the membrane and a shorter chain length of PEG molecules enabled the passage of PEG into the clay specimens. On the other hand, due to an insignificant change in the pore size of the membrane and relatively longer chain length of the PEG molecules, the infiltration of PEG molecules was less intense at a smaller applied suction.

\section{Acknowledgements}

The second author gratefully acknowledges financial support provided by University Malaysia Pahang and the Malaysian government for sponsoring his $\mathrm{PhD}$ studies at Cardiff University.

\section{REFERENCES}

Beamson, G., Pickup, B. T., Li, W. \& Mai, S. M. (2000). XPS studies of chain conformation in PEG, PTrMO, and PTMG linear polyethers. J. Phys. Chem. B 104, No. 12, 2656-2672.

Celina, M., Ottesen, D. K., Gillen, K. T., \& Clough, R. L. (1997). FTIR emission spectroscopy applied to polymer degradation. Polymer Degrad. \& Stabil. 58, No. 1, 15-31.

Cosgrove, T. (2005). Colloid science: principles, methods and applications. Oxford: Wiley-Blackwell.

Cui, Y. J. \& Delage, P. (1996). Yielding and plastic behaviour of an unsaturated compacted silt. Géotechnique 46, No. 2, 291311.

Cuisinier, O. \& Masrouri, F. (2005). Hydromechanical behaviour of a compacted swelling soil over a wide suction range. Engng Geol. 81, No. 3, 204-212.

Delage, P. \& Cui, Y. J. (2008a). An evaluation of the osmotic method of controlling suction. Geomech. and Geoeng. 3, No. 1, $1-11$.

Delage, P. \& Cui, Y. J. (2008b). A novel filtration system for polyethylene glycol solutions used in the osmotic method of controlling suction. Can. Geotech. J. 45, No. 3, 421-424.

Delage, P., Howat, M. \& Cui, Y. J. (1998). The relationship 
between suction and swelling properties in a heavily compacted unsaturated clay. Engng Geol. 50, No. 1-2, 31-48.

Dineen, K. \& Burland, J. B. (1995). A new approach to osmotically controlled oedometer testing. Proc. 1st Int. Conf. on Unsaturated Soils, Paris, 2, 459-465.

Elimelech, M., Zhu, X., Childress, A. E. \& Hong, S. (1997). Role of membrane surface morphology in colloidal fouling of cellulose acetate and composite aromatic polyamide reverse osmosis membranes. J. Membrane Sci. 127, No. 1, 101-109.

Fleureau, J. M., Kheirbek Saoud, S., Soemitro, R. \& Taibi, S. (1993). Behavior of clayey soils on drying-wetting paths. Can. Geotech. J. 30, No. 2, 287-296.

Han, S., Kim, C. \& Kwon, D. (1995). Thermal degradation of poly(ethyleneglycol). Polymer Degrad. \& Stabil. 47, No. 2, 203-208.

Harris, J. M. (1992). Poly (ethylene glycol) chemistry: biotechnical and biomedical applications. New York: Plenum.

Himmel, M. E. \& Squire, P. G. (1988). Size exclusion parameters. J. Chromatog. Lib. 40, 3-22.

Iwata, S., Tabuchi, T. \& Warkentin, B. P. (1988). Soil-water interactions: mechanisms and applications. New York: Marcel Dekker.

Kassiff, G. \& Ben Shalom, A. (1971). Experimental relationship between swell pressure and suction. Géotechnique 21, No. 3, 245-255.

Kemper, W. D. \& Evans, N. A. (1963). Movement of water as affected by free energy and pressure gradients: III. Restriction of solutes by membranes. Proc.Soil Sci. Soc. Am. 27, No. 5, 485-490.

Kim, K. J., Fane, A. G., Ben Aim, R., et al. (1994). A comparative study of techniques used for porous membrane characterization: pore characterization. J. Membrane Sci. 87, No. 1-2, 35-46.

Lentsch, S., Aimar, P. \& Orozco, J. L. (1993). Separation albumin-PEG: transmission of PEG through ultrafiltration membranes. Biotechnol. and Bioengng 41, No. 11, 1039-1047.

Marcial, D., Delage, P. \& Cui, Y. J. (2002). On the high stress compression of bentonites. Can. Geotech. J. 39, No. 4, 812-820.
Michel, B. E. \& Kaufmann, M. R. (1973). The osmotic potential of polyethylene glycol 6000. Plant Physiol. 51, No. 5, 914-916.

Minagawa, K., Matsuzawa, Y., Yoshikawa, K., Khokhlov, A. R. \& Doi, M. (1994). Direct observation of the coil-globule transition in DNA molecules. Biopolymer 34, No. 4, 555-558.

Monroy, R., Ridley, A., Dineen, K. \& Zdrakovic, L. (2007). The suitability of the osmotic technique for the long term testing of partly saturated soils. Geotech. Test. J. 30, No. 3, 220-226.

Morrison, R. T. \& Boyd, R. N. (1983). Organic chemistry. Boston, MA: Allyn \& Bacon.

Roberts, J. D. \& Caserio, M. C. (1965). Basic principles of organic chemistry, . Menlo Park, CA: W. A. Benjamin.

SL (Spectrum Laboratories Inc.) (2007). Spectralpor ${ }^{\circledR}$ 1, 2, 3, 4, 5 , 6 , and 7 regenerated cellulose (rc) dialysis membrane. Spectrum product instruction booklet. Spectrum Laboratories, Inc., Rancho Dominguez, CA, USA.

Slatter, E. E., Jungnikel, C. A., Smith, D. W. \& Allman, M. A. (2000). Investigation of suction generation in apparatus employing osmotic methods. In Unsaturated Soils for Asia: Proceedings of the 1st Asian Conference on Unsaturated Soils (UNSAT-ASIA 2000) (Rahardjo H., Toll D. G. \& Leong E. C. (eds)), pp. 297-302. Rotterdam: Balkema.

Squire, P. G. (1985). Hydrodynamic characterization of random coil polymers by size exclusion chromatography. Methods Enzymol. 117, 142-153.

Tarantino, A. \& Mongiovi, L. (2000). A study of the efficiency of semi-permeable membranes in controlling soil matrix suction using the osmotic technique. In Unsaturated Soils for Asia: Proceedings of the 1st Asian Conference on Unsaturated Soils (UNSAT-ASIA 2000) (Rahardjo H., Toll D. G. \& Leong E. C. (eds)), pp. 303-308. Rotterdam: Balkema.

Williams, J. \& Shaykewich, C. F. (1969). An evaluation of polyethylene glycol (P.E.G.) 6000 and P.E.G. 20,000 in the osmotic control of soil water matric potential. Can. J. Soil Sci. 102, No. 6, 394-398.

Zur, B. (1966). Osmotic control of the matric soil water potential: I. Soil-water system. Soil Sci. 102, No. 6, 394-398.

\section{WHAT DO YOU THINK?}

To discuss this paper, please email up to 500 words to the editor at journals@ice.org.uk. Your contribution will be forwarded to the author(s) for a reply and, if considered appropriate by the editorial panel, will be published as a discussion. 